\title{
Teachers' Perceptions on Social Skills and Problematic Behavior
}

\author{
Marta Bej
}

\author{
Doi:10.5901/jesr.2016.v6n2p125
}

\begin{abstract}
The aim of this study is to examine the teachers' perceptions of social skills, problematic behavior and discipline in the school environment. It describes the teachers' perceptions on positive and negative behavior, and management intervention strategies with the use of rewards, praise, implementation of specific techniques and sometimes punitive methods. Themost unique contribution of this study is the in-depth data that provide specific descriptions of the teachers'perceptions. Findings indicated that the teachers in this study tend to perceive themselves as strong influences in students' behavior at school. They also perceived problematic behavior through disrespectful actions during the lesson. As for a positive discipline used school wide, teachers reported not having one, and the only way of discipline was individual inside the classroom and dependable on the situation, which sometimes was managed with punitive interventions. In addition, teachers were unfamiliar with education programs that provide training on positive interventions to change problematic behaviors. Lastly, meeting teachers' training needs for implementation of Positive Discipline and use of positive strategies of interventions recommended.
\end{abstract}

Keywords: teachers' perceptions, positive behavior, social skills, positive discipline, intervention strategies.

\section{Introduction}

Our social skills are critical to successful functioning in life. Managing to have good ones, is way more beneficial, because they enable us to know what to say, how and when to say it, and also how to behave in different social situations. As the adults know their importance in life, children learn how to improve them in their everyday journey through their behavior, social and family relationships. One of the best environments where children can learn how to possess good social skills is the school environment, and especially one that provides quality and safety. But, how can the school help a child to build these skills, and shape them into successful, contributing members of their community?

Schools are one of the best resources to help students learn about themselves and grow as much as they can as individuals of the society. Grubrium \& Buckholdt (1997)see schools as a place for socialization and a place to prepare students for life, classes help students broaden their academic horizons while friends and peer groups help students develop important social skills. The development of a student's social skills transpires through interactions with parents, sibling, relatives, and peers (Powless \& Elliot, 1993). Teachers and parents can work in collaboration to encourage and nurture the development of social skills in children, and by doing so they can stimulate the growth of effective skills, by providing the student with a range of learning experiences inside and outside the classroom (Bhargava,2010). The greater benefits of social skills instruction is that it can improve both the academic and social functioning of individual students and improve the interpersonal climate of the classroom for all the students (Siperstein \& Rickards, 2004).Problems such as violence, vandalism, bullying, antisocial behaviour, poor development of pro social skills, create an unsafe learning environment, and it may predict later maladjustment in children's life (Hawkins, Catalano \&Miller 1992), as studies have demonstrated, young children with untreated behaviour problems often might experience significant adjustment problems and psychopathology(Sprague \& Walker, 2000; Tobin \&Sugai, 1999).

Often problem behaviours become more entrenched in a student's repertoire over time, and so early identification and treatment is imperative to ensure positive future outcomes (Forness et al., 2000). Consequently teachers, in many cases serve as key points, or the frontline defence for intervening with those behavioural or emotional difficulties. If they have the appropriate training and resources, the outcomes are even better. An in depth understanding of teachers' perceptions of behaviour, is crucial to ensure that teachers meet the challenge of prevention and early intervention (Tillery, Varjas, Meyers, Collins; 2010), and we should also keep in mind that their perspectives likely influence their choice of behaviour management strategy (Tillery et al., 2010).

Studies have shown that some teachers view student behaviour from a developmental perspective, such as the milestones that the child has to reach, in order that he/she must progress through the developmental stages in life (Skinner \& Hales, 1992). And sometimes, they see the behaviour, as some kind of a response that the child does, due to his/her disability, or to a certain pathology syndrome. With such kind of perspective, teachers may believe that they have 
limited or no power to modify their students behaviour, and also by considering the environment as having a greater role in behaviour problems, sometimes teachers choose not to intervene at all.

Even though that in the literature it has been reported that most teachers try to recognize the importance of effective behaviour management by preferring positive interventions (Rosen, Taylor, O'Leary \& Sanderson, 1990), there are many cases when teachers tend to deliver low rates of praise (Gunter \& Jack, 1994; Hardman \& Smith, 1999), or even using management strategies that are often punitive, for example time out, restraint, removal of privileges (etc) (Jack et al., 1996; Nungesser \& Watkins, 2005; Rosen et al., 1990).

UNICEF/Albania commissioned an important study of children and violence which was carried out by the Albania Human Development Center in 2005/2006. The study provides an excellent and informative analysis of "violence against children" in Albania. According to this study conducted by Tamo and Karaj (2006) the percentage of violence in home and schools varies from $27 \%$ to $38.2 \%$, which means that one in four children gets abused in the family environment and two in five children get abused in the school environment, where different forms of abuse are present, like: being hit in the head, spanking, pushing and pulling by force or being hit with various objects.

As another major problem, is considered also the use of psychological abuse, by offending, threatening, using nicknames, and cursing students, in order to draw their attention, or seen as effective ways, that teachers can discipline the classroom (Tamo; Karaj, 2006). When asked about the reasons for using violence, some of the teachers explained that it was the only way that the attention of the classroom could be obtained or, because, by using it they could stop dislikeable behaviors. So, according to the study mentioned above, many teachers perceive the situation as very difficult to manage, and by punishing the students they can gain the tranquility and attention needed in order to proceed with the lesson.

But, other studies show that by training and preparing properly to on-the-job experience, some teachers have learned how to utilize positive strategies to reinforce appropriate behavior and discourage negative behavior (Chafouleas, Riley-Tillman, \&Sassu, 2006).Effective classroom management relies on dealing with students as a group and is more preventive than reactive (Emmer \&Stough, 2001). What is more important is the fact that teachers should be properly trained and educated in order to have the necessary information, and knowledge in classroom management combined with effective school discipline policies, to maintain a cycle of positive interactions. Even though there is a need for in-depth data regarding general education teachers' perceptions and approaches to behavior management, to enhance teacher training practices for the development and effective implementation of schoolwide approaches to behavior management and intervention (Tillery et al., 2010), expectations for general education to undertake a prevention-focused initiative, is a formidable task that requires extensive support from all teachers (Sugai\& Horner, 2002).

\section{Purpose}

The purpose of this study was to explore teachers' perceptions regarding social skills developed in the classroom, and also management and intervention of problematic behaviour. The study was focused on teachers' perceptions because teachers are in a position to be key facilitators for prevention-focused indications, especially when these behaviours are identified at the early stages of development.Because teacher's perspective influence in the way they manage behaviour problems in classrooms and encourage the growth of social skills, it is very important to explore these perceptions through interviews designed to examine their knowledge on positive and negative behaviours, and also on how to encourage and build strong social skills. Therefore, it is important to gain further understanding of teachers' perceptions related to behaviour and intervention strategies to inform prevention and intervention practices and plan for implementation of school wide positive behaviour interventions and supports (Tillery et al., 2010).

\section{Method}

\subsection{Participants}

This article is a qualitative research. The reason for choosing this method is because we can analyse in depth the results and examine better the perceptions of the participants. Qualitative method can give a better panorama to the events and the way how these events are perceived is seen in a map of impression of the subjects invited to participate. This study was conducted in four Albanian junior high schools, located in Tirana. The researcher used simple random sampling to select the schools, and also the teachers who would serve as participants of the study. A letter was sent to each school administrator, explaining the purpose of the study, and after a few days they were contacted to further explain the study, 
answer questions and grant permission to proceed.At each school a number of 5 teachers was selected randomly from an available list, given to us by the principal of the school. The teachers were contacted through email. The final numbers of the participants were 20 junior high schools teachers, teaching from $6^{\text {th }}$ to $9^{\text {th }}$ grade. Informant consent was presented to the participants prior to their involvement. Demographic information was collected via questionnaire.

\subsection{Data collection}

Utilizing qualitative methodology, this research design involved face-to-face interaction with the participants, through semi structured interviews, to examine their perceptions of behaviour management, social skills, problem behaviour and school discipline in general. Some of the questions examined the factors causing the development of negative and positive behaviour, encouragement of good social skills, strategies they use to promote positive behaviour, and strategies they used to interrupt or prevent negative behaviour. Some of the questions were: "Describe behaviour in school", "What are some things that cause the development of positive/negative behaviour in schools?", " How do you perceive the discipline in the school environment?", "How do you support positive behaviour in the classroom?", "Give an example on how you have supported positive behaviour?", "Do you use punitive methods with your students?", "For what purpose is the use of punishment in your classroom?", "How important do you consider the growth of social skills in the classroom?", "What intervention forms, or manners do you use for encouraging good social skills?","What do you think are the main factors for the development of social competence in school?", "How do you interrupt problem behaviour in the classroom?", "How do you prevent negative behaviour in the classroom?", "Tell me about your classroom management system", "What kinds of training have you received in behaviour management?".

The interviews, which ranged in duration from 40 to 65 minutes (average one hour), were conducted by the researcher in the school environment, at sites chosen by the participants, mostly at the psychologists office, or in a school classroom. Each interview, by consent, was tape-recorded and transcribed verbatim, in order to proceed later with the data analysis.

\subsection{Data Analysis}

After verbatim transcription of all data from the conducted interviews themes and codes were developed using a deductive-inductive approach to data analysis and interpretation of the interviews (Natasi, 1999; Tillery et al., 2010). The interviews were collected, compared and analysed according to the principles of grounded theory. First, a framework of categories was developed based on the research questions that were derived through the review of empirical and theoretical literature (Tillery et al., 2010).

After careful reviewing of the transcripts, emerging themes in the data were placed in the appropriate categories. Based on these data, new codes were developed and existing codes were revised, using the constant comparison method, until the coders reached agreement on coding system after all the procedure. The categories were compared and revised until a final classification was reached, in which most of the concepts were grouped into compressed categories (Figure 1).

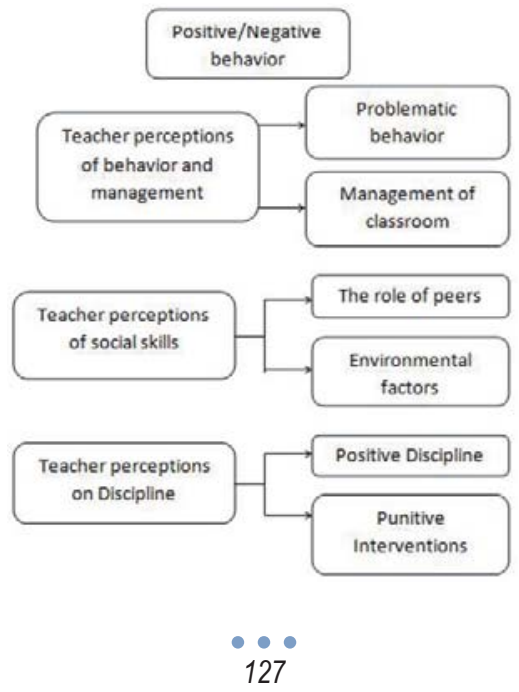




\section{Results}

The coding hierarchy reflecting teachers' perceptions on discipline and behaviour management consisted on three primary categories: (a) The teachers' perceptions of behaviour, (b)The teachers' perceptions on social skills and (c) The teachers' perceptions of Discipline. According to these main categories, the analysis identified also subthemes for each theme, presented in the figure 1 .

\subsection{Teachers' perceptions of behaviour}

The teachers' perceptions of behaviour were described in terms of positive and negative behaviour, problematic behaviour, and strategies used as interventions to class management. Behaviour, was largely defined as "how a student acts in the classroom". This was the overall response, with some minor differences on situational factors like "depends on the situation", or "in response to a certain stimull". Regarding to positive and negative behaviour, teachers reflected their perceptions in the context of school and classroom environment. They described negative behaviour as "not listening the lesson", "not concentrating during the lesion", "making noise, moving and not complying".

As for the problematic behaviour, which also was in the focus of our study, teachers described it as "being disrespectful, name calling, constantly ignoring directions, refusing to follow the rules, hitting other students, screaming and disobeying..". Problematic behaviour was depicted as "always out of the seat...Not learning at all... Mocking the students and the teacher..." Also adding "antisocial behaviour, aggression toward peers and teachers..." As a teacher stated:

\footnotetext{
"..I have this student. He is always on a rush, always so impulsive, doesn't want to listen, and we always catch him beating and bullying other students. He is very aggressive. He has no interest on school subjects, and as much as we send him to the principle or talk to his parents, he still remains the same.. He has such a problematic unmanageable behaviour..."
}

The teachers in this study reported that if the frequency of negative behaviour is high, and they keep reoccurring, than that behaviour is considered highly problematic.

Asked about the management strategies of the classroom, the teachers reported utilizing a number of behaviour management strategies. Including individual strategies (strategies shaped by experience, and not belonging to any particular theory), group strategies, peers strategies and preventive strategies. Individual strategies were used with certain students, in order to change their problematic behaviour, by talking to them and explaining the importance of school and lessons, by helping them with their homework, trying to engage them during the lesion, and sometimes reinforcing their positive behaviour with praises or rewards. There are also cases, when teachers have reported on using punitive methods like talking tough floor being rough in order to bring a change to the students behaviour.

"..I once had a very tough student who refused to sit and stay quiet. This behaviour started to repeat almost every day, and I began warning him about the consequences. One day I lost my temper and started threatening that I would call his parents and have him excluded from school. It was the hardest time I have ever had with a student..."

Some teachers reported using group and peers strategies, by trying to reduce problematic behaviour, forming groups of students where problematic students are included in order to engage them in classroom works. Some teachers reported that when these methods aren't resultative they might allow several warnings before going to the discipline system, or depending on the situation they can even take immediate action.

\subsection{Teacher's perceptions on social skills}

Social skills develop over time. Tasks that are crucial for mastery of social skills emerge at various points on the developmental continuum. The school environment is one of the most important shaping environments of these skills, and by helping students achieving them; it helps them also reach emotional maturation. Asked about how they perceive social skills, the teachers reported that they view social skills as ".. The skills a student must have, in order to complete its personality and function properly in the society...", "The skills needed to form social interaction".

Through the interviews teachers highlighted the role of peers, as one of the most influential factors on building social skills. As a teacher stated: 
".. I see my students working on perceiving themselves as capable, significant, and in control of their life, but after some time, they understand that, even though they try in every way possible, they end up building these skills with social interaction, and in peer groups".

Group of peers also help students develop a sense of identity and understand the other person's beliefs and emotion, "sometimes, students learn through social interactions, how to be empathic, and that is an important quality". Asked about the main factors that influence the development of social competence in students, a teacher stated:

\begin{abstract}
"..I believe that there are many factors that contribute on building strong social competence, first in the family environment, having supportive parents who understand the students' needs and encourage him/her to always to his best and always try to succeed, even thoughts not always meant to. Also the school environment plays an important role, by having an understanding teacher who motivates the students and by encouraging them to express themselves..."
\end{abstract}

Another question was about interventions that teacher can use, in order to help the growth of social skills, and they reported that some of the interventions used were "engaging in social activities with other students, trying to increase social interaction, getting to know the students interests and areas of competence..." About the other factors were environmental ones, where the most important was considered "having a friendly, respectful, encouraging, positive, and in harmony environment... Where students get to know each other, learn and play and feel good at the same time..."Almost every teacher stated that building social skills is one of their most important duties, because they feel responsible for their students prosperity as members of the society and individuals as well.

\title{
4.3 Teachers' perceptions on Discipline
}

Discipline was another field in which teachers' perceptions were asked, in terms of positive discipline, how they perceive it, and punitive interventions, when are they needed and do teachers apply them? Most of the teachers perceived positive discipline as teaching students positively, by "reinforcing good behaviours, and praising and providing them with positive models of behaviour..." Other typical answers to this question were: "positive discipline is anything that can encourage the students to do the right thing and to behave properly...by saying I would want you to do... And if the student changes his behaviour than it's done..." The teachers were large unfamiliar with programs of positive discipline and interventions; they mostly perceived it as a way of positive behaviour with positive results, but not with direct interventions on how to get to those results. Asked about positive discipline applied with students with problematic behaviours most of teachers stated that, such kind of a model was ineffective and they used other discipline strategies that were sometimes even harsher. For example a teacher stated:

"Sometimes students choose not to listen, even when you speak nicely to them, and try to make them understand that what they are doing is wrong and they should change it. Is at this time when I start using punishment, by not letting him play with other friends, and giving him more tasks to do...Sometimes this works, but sometimes it makes the job harder..."

Another teacher stated: "If I want to keep the class quiet, I just open the classroom door, and tell them that they are free to leave, or I keep the door open for the principal to come and check on the lesson" When asked about what they think on punitive interventions, teachers reported that "sometimes you got to show authority, or otherwise they won't obey, and will keep destructing everyone in the class", "at times is the only way, you can maintain the class quiet, and interrupt disrespectful behaviour among students". So most of the teachers justify punitive interventions because they see them as way students can learn to behave, after trying other positive methods and obtained no results. Some teachers when asked about the general discipline system of the school, had difficulty answering, with saying:" We don't really have a discipline policy in the school, so we only have our discipline in our individual classrooms, but not a schoolwide one". Which means lack of discipline interventions programs, necessary for maintaining difficult situations under control?

\section{Discussions}

The purpose of this study was to examine teachers' perceptions on social skills, problematic behaviour, discipline method and intervention strategies to a healthy learning. There is a lot of existing literature that has examined teacher's 
perceptions of students' problem behaviour and interventions (Kokkinos, Panayiotis, \&Davazoglou, 2005; Little, 2005; Lopes et al., 2004). The qualitative data derived from this investigation make several contributions to the research concerning discipline methods in Albania, how teachers perceive students behaviour and what strategies they use to shape it. First we collected teachers' perceptions on positive and negative behaviour, including problematic one, and what are some of the ways used to manage it. Second, greater consideration was given to the perception and build of strong social skills, by implementing strategies including peer groups and environmental factors. Third, the teachers in this study were asked about positive discipline and punitive interventions, the reasons after each and need for a schoolwide effective discipline system. The in-depth examination and description of general teacher's perceptions on behaviour and its management, is a unique addition to the research literature related to behaviour management. The themes that emerged from the data in this study, are the supporting quotes generated by the teachers captured their perspectives about behaviour, its influencing factors and management strategies. The teachers provided a broader range of descriptions of behaviour management strategies for individual students, whereas strategies directed to groups of children or schoolwide approach were limited.

Perception of positive behaviour was expressed in terms of "acting positively, and in accordance with the rules", without having information on trainings and appropriate techniques teachers can use to promote it. Also intervention strategies, were mostly based on the experience in class management, and not in particular developed programs for a particular behaviour. The individual strategies teachers used may have developed as a result of the strategies that they acquired during their beginning years as teachers by learning to cope with demands as they arose and by observing veteran teachers (Garrahyetl al., 2005; Tillery et al., 2010).

The finding that teachers perceived social skills, as important skills shaping an individual is also in accordance with the existing literature on development of social competence. Even in this study teachers reported that "social skills are needed to create a sense of membership in the society, and a sense of self in managing different situations". As literature research states "Strong social skills help students in perceiving themselves as capable, significant and in control of their life, also developing skills of self-control, cooperation, and adaptability.But, it also helps the teachers to set a classroom climate where there is acceptance, respect, and encouragement. Teachers learn how to demonstrate caring by talking with students, showing personal interest in their achievements and facilitating the relationships by removing the existing barriers" (Charles and Senter,2005).

The teachers in this study also reported the need for further training methods in order to stop punitive interventions, which were used when "nothing else could be done", and replace it with effective interventions to achieve the expected behaviour. In addition to addressing teachers' needs through ongoing intensivetraining and support, teacher training programs should consider the present paradigm shift that is moving away from reactive strategies and toward preventive school wide approaches to behaviour management and adjust instruction accordingly (Tillery et al., 2010). Teachers viewed themselves as strong influences in students' behaviour at school, and by having high expectations for their students, building a warm welcoming and cooperating environment,they could find the key factors in encouraging positive behaviours, good social skills, and a greater discipline model for themselves and their students.

\section{References}

Barghava.D, (2010), "Teaching students with sensory impairments; Social skills", Renwick College.

Chafouleas, S., Riley-Tillman, T. C., \&Sassu, K. (2006), "Acceptability and reported use of daily behaviour report cards among teachers ", Journal of Positive Behavioural Interventions, No.8,pg 174-182.

Charles.C.M, Senter.G.W, (2005), "Building classroom discipline: Overview of Nelsen, Lott and Glenn's model", Pearson.

Emmer, E., \& Stough, L. (2001), "Classroom management: A critical part of educational psychology, with implications for teacher education", Educational Psychologist, №. 36, pg103-112.

Forness, S. R., Serna, L. A., Nielsen, E., Lambros, K., Hale, M. J., \&Kavale, K. A. (2000),"A model for early detection and primary prevention of emotional and behavioural disorders", Education \& Treatment of Children, No.23, pg325-346.

Garrahy, D., Cothran, D., \&Kulinna, P. (2005), "Voices from the trenches: An exploration of teachers' management knowledge", Journal of Educational Research, No.99, pg56-63.

Gubrium, J. F., \&Buckholdt, D. R. (1977), "Toward Maturity", San Francisco, CA: Jossey-Bass Publishers.

Gunter, P. L., \& Jack, S. L. (1994), "Effects of challenging behaviours of students with EBD on teacher instructional behaviour", Preventing School Failure, No.38, pg35-40.

Hardman, E., \& Smith, S. (1999), "Promoting positive interactions in the classroom", School \& Clinic, No.34, pg178-181.

Hawkins.J.D, Catalano.R.F, Miller.J.Y, (1992), "Risk and protective factors for alcohol and other drug problems in adolescence and early childhood: Implications for substance abuse prevention", Psychological Bulletin.

Jack, S. L., Shores, R. E., Denny, R. K., Gunter, P. L., De Briere, T., \&De Paepe, P. (1996), "An analysis of the relationship of teachers' 
reported use of classroom management strategies on types of classroom interactions", Journal of Behavioural Education, No.6, pg67-87.

Kokkinos, C. M., Panayiotou, G., \&Davazoglou, A. M. (2005), "Correlates of teacher appraisals of student behaviours", Psychology in the Schools, No.42, pg 79-89.

Little, E. (2005), "Secondary school teachers' perceptions of students' problem behaviours", Educational Psychology, No.25, pg369-377.

Lopes, J. A., Monteiro, I., Sil, V., Rutherford, R. B., \& Quinn, M. M. (2004), "Teachers' perceptions about teaching problem students in regular classrooms", Education and Treatment of Children, No.27, pg394-419.

Nastasi, B. K., \&Schensul, S. L. (2005), "Contributions of qualitative research to the validity of intervention research", Journal of School Psychology, No.43, pg 177-195.

Nungesser, N., \& Watkins, R. (2005), "Preschool teachers' perceptions and reactions to challenging classroom behaviour: Implications for speech-language pathologists", Language, Speech, and Hearing Services in Schools, No.36, pg139-151.

Powless, D. L. \& Elliot, S. N. (1993), "Assessment of social skills of Native American preschooler: Teachers' and parents' ratings", Journal of School Psychology, 31, 293-307.

Rosen, L., Taylor, S., O'Leary, S., \& Sanderson, W. (1990), "A survey of classroom management practices", Journal of School Psychology, No.28, pg257-269.

Rosen, L., Taylor, S., O'Leary, S., \& Sanderson, W. (1990), "A survey of classroom management practices", Journal of School Psychology, No.28, pg257-269.

Siperstein, G. N. \& Rickards, E. P. (2004). "Promoting social success: A curriculum for children with special needs", Baltimore, MD: Paul H. Brookes Pub. Co.

Skinner, M., \& Hales, M. (1992), "Classroom teachers' explanations of student behaviour: One possible barrier to the acceptance and use of applied behaviour analysis procedures in the schools", Journal of Educational and Psychological Consultation, No.3,pg 219-232.

Sprague, J., \& Walker, H. (2000),"Early identification and intervention for youth with antisocial and violent behaviour", Exceptional Children, No.66, pg367-380.

Sugai, G., \& Horner, R. (2002), "The evolution of discipline practices: School-wide positive behaviour supports", Child \& Family Behaviour Therapy, No.24, pg23-50.

Tamo.A, Karaj. Th, (2006), "Dhuna kundër fëmijëve në Shqipëri", Qëndra e zhvillimeve humane, UNICEF Shqipëri.

Tillery.A.D; Varjas.K; Meyers.J; Collins.A.S, (2010), "General Education Teachers' Perceptions of Behaviour Management and Intervention Strategies"; Journal of Positive Behaviour Interventions, Vol.12, No.2, pg 86-102.

Tobin, T. J., \&Sugai, G. M. (1999), "Using sixth-grade school records to predict school violence, chronic discipline problems, and high school outcomes", Journal of Emotional \&Behavioural Disorders, No.7, pg41-55. 
